\title{
Estudo comparativo de detecção de metapneumovírus humano pelos métodos de PCR e imunofluorescência direta
}

Primeira submissão em 21/09/10 Última submissão em 21/03/11 Aceito para publicação em 05/04/11 Publicado em 20/08/11

\section{Comparative study of human metapneumovirus detection by PCR and direct immunofluorescence methods}

Sheila Negrini Parmezan'; Jacyr Pasternak2; Ana Helena Perosa Dezene ${ }^{3}$; Marinês Dalla Valle Martino4; Andrea Vieira de Souza ${ }^{5}$

\begin{tabular}{l}
\multicolumn{1}{c}{ unitermos } \\
Metapneumovírus humano \\
Infecções respiratórias \\
Diagnóstico molecular \\
de vírus
\end{tabular}
de vírus

\section{resumo}

Introdução: O metapneumovírus humano (MPVh) causa infecções respiratórias em crianças, adultos e idosos imunodeprimidos. O diagnóstico é realizado por imunofluorescência (IF) ou biologia molecular. Objetivo: Detectar o MPVh em amostras clínicas pelos métodos de reação em cadeia da polimerase (PCR) e imunofluorescência direta (IFD). Resultados: Das 202 amostras, a positividade foi de $2 \% \mathrm{e}$ $4 \%$ para IFD e RT-PCR, respectivamente. Sensibilidade e especificidade da IFD foram de 50\% e 100\%, respectivamente, considerando o PCR com transcrição reversa (RT-PCR) como padrão-ouro. Conclusão: O estudo indica a RT-PCR como o melhor método para a identificação de MPVh em amostras clínicas respiratórias e mostra a importância da padronização do teste para inclusão na rotina laboratorial.

\section{abstract}

Introduction: Human metapneumovirus (HMPV) is responsible for respiratory infections in children and immunocompromised adults and elders. It is commonly diagnosed by immunofluorescence or molecular biology. Objective: To detect HMPV in clinical samples by polymerase chain reaction (PCR) and direct imunofluorescence (DIF) methods. Results: Two percent of 202 samples were positive for DIF and $4 \%$ of them for reverse transcriptase $P C R(R T-P C R)$, respectively. Considering RT-PCR as gold standard, DIF sensitivity and specificity were $50 \%$ and $100 \%$, respectively. Conclusion: Not only does the study show that RT-PCR is the best method for HMPV detection in clinical respiratory samples but it also substantiates the importance of test standardization in laboratory routine.

\section{key words}

Human metapneumovirus

Respiratory infections

Virus molecular diagnosis

\footnotetext{
1. Farmacêutica-bioquímica; analista de laboratório do Hospital Israelita Albert Einstein.

2. Doutor em Medicina; infectologista do laboratório clínico do setor de Microbiologia do Hospital Israelita Albert Einstein.

3. Mestra em Ciências da Saúde pela disciplina de Doenças Infecciosas e Parasitárias da Universidade Federal de São Paulo/ Escola Paulista de Medicina (UNIFESP/EPM); pesquisadora.

4. Professora adjunta da disciplina de Microbiologia da Faculdade de Ciências Médicas da Santa Casa de São Paulo (FCMSCSP); coordenadora-médica do setor de Microbiologia do Laboratório Clínico do Hospital Israelita Albert Einstein.

5. Mestra em Ciências pela Universidade de São Paulo (USP); pesquisadora assistente do Instituto Israelita de Ensino e Pesquisa Albert Einstein.
} 


\section{Introdução}

Os vírus respiratórios são os patógenos diagnosticados com maior frequência e o diagnóstico etiológico requer confirmação laboratorial, pois apenas com o quadro clínico não é possível reconhecer a etiologia da doença ${ }^{(18)}$. Os vírus respiratórios mais comumente diagnosticados são influenza (Flu), rinovírus, parainfluenza vírus (PIV), vírus sincicial respiratório (VSR), adenovírus (AdV) e metapneumovírus $(\mathrm{MPVh})^{(6,18)}$.

O metapneumovírus foi relatado pela primeira vez em 2001, causando infecção em crianças, adultos e idosos imunocomprometidos e portadores de doença crônica $^{(5)}$. A sazonalidade é semelhante à do VSR, que circula de abril a junho nos países da América do Sul ${ }^{(1,14)}$. A prevalência varia mundialmente de $2,2 \%$ a $43 \%$ em amostras respiratórias $(2,14,15)$

O isolamento viral em cultura de células é considerado padrão-ouro para o diagnóstico laboratorial de alguns vírus, porém, o MPVh mostra pouca ou nenhuma replicação e variação no efeito citopático ${ }^{(19)}$. A detecção de antígenos por imunofluorescência (IF) é utilizada na rotina laboratorial por ser um método fácil e de rápido resultado ${ }^{(10,13)}$. Porém, os métodos moleculares têm sido os mais utilizados, devido a sua alta sensibilidade e especificidade ${ }^{(7)}$. Os objetivos deste estudo foram detectar a presença de MPVh em amostras encaminhadas para triagem de vírus respiratórios e comparar a sensibilidade e a especificidade dos dois métodos diagnósticos utilizados.

\section{Materiais e métodos}

\section{Amostragem}

Foram analisadas amostras de swab nasal, secreção traqueal e aspirado nasofaríngeo no período de 1 de junho a 30 de julho de 2009. Foram incluídas amostras relacionadas com o exame de triagem de vírus respiratório de crianças de 0 a 5 anos, idosos e adultos imunocomprometidos e excluídas as amostras com volume insuficiente e de pacientes acima de 6 anos que não faziam parte do grupo de risco.

\section{Imunofluorescência direta}

A pesquisa de antígenos de vírus respiratórios (VSR, influenza, adenovírus e parainfluenza) foi realizada adequadamente e as lâminas foram preparadas conforme a rotina de trabalho, sendo uma para a realização da triagem viral (Screen Respiratory Virus Imagen, Oxoid) e uma com antígenos específicos de cada vírus. Uma terceira lâmina foi preparada para a pesquisa de MPVh (Imagen, Oxoid).

\section{RT-PCR para MPVh}

A extração do ácido nucleico (RNA) foi realizada a partir de $140 \mu \mathrm{l}$ da amostra para a extração de RNA total, com o Qiamp RNA Viral Mini Kit (Qiagen), de acordo com as especificações do fabricante. A transcrição reversa foi realizada utilizando o High Capacity cDNA Archive Kit (Applied Biosystems), no qual a amplificação ocorre a partir de primers randômicos e transcriptase reversa recombinante rMoMuLV (Moloney Murine Leukemia Virus), segundo as especificações do fabricante.

Como controle da eficiência da reação de extração de RNA, foi realizada a amplificação do gene da beta-actina humana em todas as amostras segundo Raff et al.(17) e os primers utilizados para a detecção de MPVh foram descritos por Falsey et al.(9) para a amplificação de um fragmento de 347 pb do gene da proteína F de MPVh.

\section{Análise de dados}

Foram calculados os valores de sensibilidade, de especificidade e preditivos positivo e negativo a partir de uma tabela dois por dois em software Microsoft Office Excel, versão 2000, e os índices de concordância e Q-quadrado, em software Statistical Package for the Social Sciences (SPSS), versão 17.0. Valor de $p<0,05$ foi considerado significativo.

\section{Resultados}

Foram incluídas 202 amostras de 191 pacientes, 92 do sexo feminino (47\%), cuja idade média correspondeu a 3,68 anos e a mediana igual a 1 ano, com variação de 2 dias a 84 anos de idade. Entre os 202 exames realizados pelo método de imunofluorescência direta (IFD) para vírus respiratórios, 39\% (78) apresentaram resultado positivo e $2 \%$ (quatro amostras) destes foram positivos para MPVh. Paralelamente aos testes de IFD, foi realizada a reação em cadeia da polimerase com transcrição reversa (RT-PCR) convencional para MPVh, que obteve positividade de $4 \%$.

Para a análise estatística, considerou-se padrão-ouro o método de RT-PCR, assim os resultados de sensibilidade, especificidade, concordância e Q-quadrado foram $50 \%$, $100 \%, 0,658$ e valor de $p<0,001$, respectivamente. Todas 
as amostras positivas por IF o foram por RT-PCR. O valor preditivo positivo da IF foi de $100 \%$ e o valor preditivo negativo, $97,98 \%$.

\section{Discussão}

O período de sazonalidade do MPVh ocorre paralelamente ao do VSR e isso acontece principalmente nos meses de maio e junho, sendo que alguns autores relatam aumento da sazonalidade no período de setembro e outubro no hemisfério sul ${ }^{(2,14)}$. No período em que foram realizadas as coletas, ocorreu a pandemia de influenza H1N1 e houve significativo aumento no número de atendimentos decorrentes de infecções respiratórias. Mesmo com a sobrecarga de exames, a taxa de positividade do MPVh não aumentou.

A incidência de MPVh encontrada neste estudo foi de $4 \%$, sendo que $2 \%$ das amostras identificadas na IF foram confirmadas na RT-PCR. Essa incidência é menor do que a de $10 \%$ a $17 \%$ observada em estudo com a mesma metodologia ${ }^{(4)}$ e é semelhante a 2,3\% a 3,1\% identificada em outros estudos ${ }^{(8,18)}$. Os pacientes positivos para MPVh confirmam o que muitos autores relatam sobre os grupos de risco: uma pessoa idosa (77 anos), um adulto (40 anos) e cinco crianças (0 e 5 anos) ${ }^{(6,8,9)}$.
Neste estudo, o RT-PCR foi considerado padrão-ouro para o diagnóstico de MPVh e, quando em comparação com a IF, os resultados da sensibilidade (50\%) foram menores do que os observados em outros estudos, que tiveram sensibilidade de $62,5 \%$ a $71,8 \%$. A especificidade $(100 \%)$ foi semelhante para os mesmos estudos $(99,2 \%$ a $100 \%)^{(3,11)}$.

As desvantagens da IF devem-se a múltiplos fatores, como kits comerciais, potencial de variabilidade na leitura técnica e qualidade da amostra. Vários estudos têm demonstrado o diagnóstico molecular como o melhor método para a detecção de vírus respiratórios. Isso pode ser verificado pelos resultados obtidos neste estudo. Considerando o número pequeno de amostras, o RT-PCR foi o método mais sensível, com detecção de $50 \%$ mais positivo que a $\mathrm{IF}^{(12,16)}$.

\section{Conclusão}

Mesmo com a porcentagem baixa de amostras positivas para MPVh, a pesquisa desse vírus não pode ser desconsiderada, devido ao impacto que tem sobre populações de risco e transmissões nosocomiais. O diagnóstico por IF mostrou-se de baixa sensibilidade, indicando que o melhor método para diagnóstico de MPVh é o molecular.

\section{Referências}

1. ABARA, S. Metapneumovirus humano: un nuevo agente en IRA alta y baja. Neumol Pediátr, v. 1, n. 1, p. 11-3, 2006.

2. ALBUQUERQUE, M. C. M. et al. Novel respiratory virus infections in children, Brazil. Emerg Infect Dis, v. 15, n. 5, 2009.

3. ASLANZADEH, J. et al. Prospective evaluation of rapid antigen tests for diagnosis of respiratory syncytial virus and human metapneumovirus infections. J Clin Microbiol, v. 46, n. 5, p. 1682-5, 2008.

4. BANERJEE, S. et al. Human metapneumovirus infections among children with acute respiratory infections seen in a large referral hospital in India. J Clin Virol, v. 38, n. 1, p.70-2, 2007.

5. BASTIEN, N. et al. Human metapneumovirus infections in the Canadian population. J Clin Microbiol, v. 42, p. 3532-7, 2004.

6. BROOR, S. et al. Human metapneumovirus: a new respiratory pathogen. J Biosci, v. 33, n. 4, p. 483-93, 2008.

7. CARRARO, E. Aplicação de recursos laboratoriais no diagnóstico de infecções respiratórias de etiologia viral. São Paulo, 2007. Tese (Doutoramento) - Departamento de Medicina, Disciplina de Doenças Infecciosas e Parasitárias, Escola Paulista de Medicina.

8. DARE, R. et al. Diagnosis of human metapneumovirus infection in immunosuppressed lung transplant recipients and children evaluated for pertussis. J Clin Microbiol, v. 45, n. 2, p. 548-52, 2007

9. FALSEY, A. R. et al. Human metapneumovirus infections in young and elderly adults. J Infect Dis, v. 187, n. 5, p. 785-90, 2003

10. FENWICK, F. et al. Diagnosis of human metapneumovirus by immunofluorescence staining with monoclonal antibodies in the North-East of England. J Clin Virol, v. 40, n. 3, p. 193-6, 2007.

11. GERNA, G. et al. Prospective study of human metapneumovirus infection: diagnosis, typing and virus quantification in nasopharyngeal secretions from pediatric patients. J Clin Virol, v. 40, n. 3, p. 236-40, 2007

12. INGRAM, R. M. et al. Detection of human metapneumovirus in respiratory secretions by reversetranscriptase polymerase chain reaction, indirect immunofluorescence, and virus isolation in human bronchial epithelial cells. J Med Virol, v. 78, p. 122331,2003 
13. LANDRY, M. L. et al. Prospective study of human metapneumovirus detection in clinical samples by use of light diagnostics direct immunofluorescence reagent and real-time PCR. J. Clin Microbiol, v. 46, p. 1098-100, 2000.

14. MULLINS, J. A. et al. Human metapneumovirus infection among children hospitalized with acute respiratory illness. Emerg Infect Dis, v. 10, p. 700-5, 2004.

15. OLIVEIRA, D. B. et al. Epidemiology and genetic variability of human metapneumovirus during a 4-year-long study in Southeastern Brazil. J Med Virol, v. 81, n. 5, p. 915-21, 2009.
16. PABBAJU, K. et al. Diagnosis and epidemiological studies of human metapneumovirus using real-time PCR. J Clin Virol, v. 40, n. 3, p. 186-92, 2007.

17. RAFF, T. et al. Design and testing of beta-actin primers for RT-PCR that do not co-amplify processed pseudogenes. Biotechniques, v. 23, n. 3, p. 456-60, 1997.

18. THOMAZELLI, L. M. et al. Surveillance of eight respiratory viruses in clinical samples of pediatric patients in southeast Brazil. J Pediatr (Rio J), v. 83, n. 5, p. 422-8, 2007.

19. VAN DEN HOOGEN, B. G. et al. A newly discovered human pneumo-virus isolated from young children with respiratory tract disease. Nat Med, v. 7, p. 719-24, 2001. 